\title{
Feelings, perceptions, and expectations of patients during the process of oral cancer diagnosis
}

\author{
K. M. Graner ${ }^{1}$ (D) - G. S. Rolim ${ }^{2}$ - A. B. A. Moraes ${ }^{3}$ - C. R. Padovani ${ }^{4}$ - M. A. Lopes ${ }^{5}$. \\ A. R. Santos-Silva ${ }^{5}$ - A. T. A Ramos-Cerqueira ${ }^{6}$
}

Received: 3 June 2015 / Accepted: 15 November 2015 /Published online: 27 November 2015

(C) Springer-Verlag Berlin Heidelberg 2015

\begin{abstract}
Purpose Communication barriers during the process of cancer diagnosis can adversely affect how patients understand their health, and understanding patient's perceptions and expectations can favor adherence to professional recommendations and their prognosis. This study aimed to describe the sociodemographic characteristics, perceptions, expectations, and psychological symptoms of patients during the process of oral cancer diagnosis.

Methods Patients were assessed at two time points: prebiopsy (T0) and post-diagnosis (T1). At T0, 49 patients answered a sociodemographic, perceived social support, lifestyle questionnaire and inventories (anxiety-StateTrait Anxiety Inventory (STAI-S/T), depression-Beck Depression Inventory (BDI), risk drinkers-Alcohol Use Disorders Identification Test (AUDIT)). They also were interviewed concerning their perceptions, feelings, and expectations. At T1, the 29 patients diagnosed with oral cancer were reassessed for anxiety (STAI-E) and
\end{abstract}

K. M. Graner

kmendesgra@yahoo.com.br

G. S. Rolim

gustavo.rolim@ufjf.edu.br

A. B. A. Moraes

abento@fop.unicamp.br

C. R. Padovani

padovani@ibbb.unesp.br

M. A. Lopes

malopes@fop.unicamp.br

A. R. Santos-Silva

alanroger@fop.unicamp.br

A. T. A Ramos-Cerqueira

anateresa04@gmail.com depression symptoms. An interview investigated the same aspects at $\mathrm{T} 0$.

Results Patient mean age was 59 years old $( \pm 13.7)$ and $73.5 \%$ were men. At T0, depression symptoms were more frequent among cancer patients $(83.3 \%)$ than those without the disease $(p<0.05)$, with a prevalence of $36.7 \%$. Patients presented anxiety (40.8\%) and alcohol abuse behavior (32.6\%). Associations between characteristics and categories at $\mathrm{T} 0$ showed that patients with lower income and living with a partner reported negative feelings $(p<0.05)$ more frequently, together with negative expectations concerning the diagnosis among older patients $(p<0.05)$ and those with depressive symptoms $(p<0.05)$. At T1, negative feelings were more frequently reported among patients with anxiety $(p<0.01)$ and depression symptoms $(p<0.05)$.

Conclusion Professional support and care regarding the psychological aspects and characteristics of patients is required during the diagnosis process in order to promote patient adhesion and favorable prognosis.

1 Botucatu Medical School, São Paulo State University (UNESP), Botucatu, Brazil

2 Department of Basic Health/Applied Psychology, Federal University of Juiz de Fora (UFJF), Governador Valadares, Brazil

3 Department of Social Dentistry, Area of Applied Psychology, Piracicaba Dental School (FOP), State University of Campinas (UNICAMP), Campinas, Brazil

4 Biosciences Institute, São Paulo State University (UNESP), Botucatu, Brazil

5 Department of Oral Diagnosis, Area of Semiology, Piracicaba Dental School (FOP), State University of Campinas (UNICAMP), Campinas, Brazil

6 Department of Neurology Psychology and Psychiatry, Botucatu Medical School, São Paulo State University (UNESP), Botucatu, Brazil 
Keywords Diagnosis communication · Perceptions · Expectations $\cdot$ Anxiety $\cdot$ Depression

\section{Introduction}

Oral cancer is one of the most common types of head and neck cancer and the sixth most frequent among all cancers. It affects the lips and oral cavity, including the gums, mucosa, hard palate, tongue, and oral floor [1]. In 2014, the National Cancer Institute estimated 2.440 new cases of oral and pharyngeal cancer in the USA. In the same year, 11,280 new cases of oral cancer were estimated in men and 4010 in women, according to the Brazilian National Cancer Institute. Known etiological factors in the development of this cancer include genetic alterations in association with behavioral factors, such as smoker and risk drinking [1-3]. A diagnosis of cancer can generate psychological repercussions for both the patients and their families $[4,5]$.

The process of cancer diagnosis begins when the patient or professional identifies the presence of an intra- or extraoral lesion that may be accompanied by pain or discomfort. It is part of the physician's job to investigate changes in the characteristics observed through clinical examination and biopsy. Following the laboratorial tests, the clinician is required to report the diagnosis to the patient and family members. A cancer diagnosis can be considered bad news, including possible limitations, losses or threats to the integrity of the individual, and conditions that can seriously affect their future and can have negative consequences during and after treatment. In addition, it is part of the physician's routine to answer questions and provide guidance on their condition and treatment $[3,6]$.

An important variable in the process of cancer diagnosis is the behavior of the clinicians who attend and inform the patient and their family, since they can facilitate or hamper understanding of the patient's health condition and adherence to recommendations for its treatment [7]. Certain factors related to clinical practice, such as insufficient time for consultation, lack of professional communication skills, and difficulty in identifying and dealing with personal characteristics (sex, age, income, education level, and the site, stage, and recurrence of the lesion) and psychosocial demands (anxiety, depression) of patients are variables that can interfere in the diagnostic process [6-10]. Younger patients, who have a higher educational level and living with a partner tend to expect detailed information about their disease [8]. It seems that these characteristics are positively associated with the degree of satisfaction with the care received $[6,11]$. Receiving psychosocial support and information in its entirety is also positively associated with the degree of patient satisfaction [12]. However, in several countries, certain aspects of the diagnosis are omitted from patients [13-15]. Cultural differences may explain the preference for maintaining aspects of the patient's health condition in confidentiality [16-20]. Training health professionals to be sensitive to these issues can help minimize barriers while communicating bad news $[9,16]$.

In order to develop the professional skills required to communicate "bad news" during the diagnostic process, studies suggest using specific protocols as a guide in this situation [21-25]. Other research has focused on the characteristics, perceptions, expectations, and emotional state of patients diagnosed with cancer [2, 3, 5-7, 9, 10, 14, 19, 20, 26-33]. However, research investigating the characteristics of patients from the initial consultation onward [34], how they perceive the information offered by health professionals concerning their health condition, their expectations, and related psychological aspects remains scarce, particularly in Brazil [7]. Therefore, this study aimed to describe the sociodemographic characteristics, perceptions, expectations, and psychological symptoms of patients during the process of oral cancer diagnosis.

\section{Method}

This cross-sectional and longitudinal study was conducted from March 2011 to October 2012, in two centers of oral cancer diagnosis in the interior of the State of São Paulo, Brazil. Both are reference institutions in the study of oral lesions. Forty-nine adult patients participated in the study, referred by dentists who observed the presence of oral lesions suspected of being cancer following clinical and radiological examinations, the only criterion for inclusion in the study. The presence of cognitive impairment or emotional manifestations that hindered adequate understanding of the information provided by health professionals and interfered in responses to the protocols was considered an exclusion criterion. This study was approved by the Research Ethics Committee of Piracicaba Dental School of the State University of Campinas (FOP-UNICAMP) under protocol no. 014/2010. The participants in this study were informed regarding the purpose of the study and the confidentiality of their personal data, and all of them signed a term of free, informed consent.

The study took place in two phases: $\mathrm{T} 0$, during which the patients attended the Diagnosis Center having been referred by dentists or doctors of different health services for a biopsy of suspected oral cancer, and $\mathrm{T} 1$, in which only patients who had a confirmed cancer diagnosis were reassessed, immediately following the announcement of the news by the dentist. At T0, patients were required to answer a questionnaire concerning sociodemographic characteristics, smoking, and social support. Next, a semi-structured interview involving open questions was conducted in order to investigate their understanding regarding the information provided by the dentist in relation to the biopsy procedure and their perceptions, feelings, and expectations concerning the diagnosis and the 
care provided by the dentist. The State-Trait Anxiety Inventory (STAI) [35], the Beck Depression Inventory (BDI) [36], and the Alcohol Use Disorders Identification Test (AUDIT) [37] were also applied.

T1 occurred about 7 days after T0, when the patient returned to receive the diagnostic result and have the suture removed. At this time, only the 29 patients with a cancer diagnosis were reassessed. These patients were reinterviewed concerning their understanding of the information provided by the dental surgeon (diagnosis and referral to a doctor), their feelings about the news, how they thought about dealing with this new situation, their expectations concerning the health professionals (dentist and doctor), and their level of satisfaction with the care they received. Patient anxiety (STAI) and depression symptoms (BDI) were also reassessed.

The interview responses obtained in both phases were audio recorded and transcribed in full for analysis. To achieve this, all the replies from the interviews were read thoroughly, searching for similarities using the structural content analysis [38]. This framework allowed the identification of the thematic categories (feelings, understanding, expectations, coping, satisfaction), which were identified as syntheses of contents with similar meanings. Those categories were then carefully analyzed, and subcategories (positive, negative) were identified indicating positive and negative aspects involved in each theme. This process allowed categories and subcategories to be analyzed quantitatively [38].

The data were analyzed using the program STATA 12.0 [39]. Where appropriate, the chi-square or Fisher's exact tests were used for descriptive and bivariate analyses. Possible differences between the frequency of anxiety and depression symptoms at $\mathrm{T} 0$ and $\mathrm{T} 1$ were studied by Goodman confidence interval for contrasts between trinomial proportions. The standard statistical significance level of $95 \%$ for rejecting the null hypothesis was adopted for all analyses.

\section{Results}

In this study, the 49 patients who participated in phase 1 had a mean age of 59 years $(\mathrm{SD} \pm 13.7)$ and were predominantly male $(73.5 \%)$. The mean education level was 4 to 7 years of schooling (mean 4.4; $\mathrm{SD} \pm 2.9$ ); $40.8 \%$ reported being employed and $38.8 \%$ were retired. The average per capita income was $\mathrm{R} \$ 670.8(\mathrm{SD} \pm 451.0)$, with $53.1 \%$ receiving less than the Brazilian minimum wage - the reference value in 2013 in São Paulo was R\$755.00 to R\$775.00. The data obtained showed that $83.7 \%$ of patients felt they had someone to share their problems with, which was regarded as perceived social support. Fifty percent of men and $30.8 \%$ of women were self-declared smokers, with an overall prevalence of $44.9 \%$. According to the instrument used to evaluate the alcohol use (AUDIT), 35.1 \% of men were considered risky drinkers, together with $23.1 \%$ of women, with an overall prevalence of $32.0 \%$. The majority of the total patient population $(n=49)$ considered their health to be "good" $(69.4 \%)$. The mean time between the observation of the lesion and the diagnosis was 140.5 days $(\mathrm{SD} \pm 173.46)$, slightly over 4 months (data not shown in tables).

Table 1 shows the sociodemographic, clinical, and psychosocial characteristics identified in T0, comparing patients according to the diagnosis they received in $\mathrm{T} 1$.

A significant difference between the two groups (with or without a diagnosis of cancer) was only verified in relation to depressive symptoms. A higher prevalence (83.3\%) of these symptoms was observed among those who received a diagnosis of cancer $(p=0.02)$, with an overall prevalence of $36.7 \%$. The overall prevalence of state-anxiety was $40.8 \%$ but was $60.0 \%$ among cancer patients. A high prevalence of alcohol abuse (32.6\%) was also observed, and among these, $62.5 \%$ were patients who were diagnosed with cancer. In addition, a high prevalence of current smoking (49.9\%) was identified, with similar distribution between the two groups. Over half of the total sample presented a per capita income below the minimum wage, while $28 \%$ had only 3 years of formal education. In addition, $66.7 \%$ of participants diagnosed with cancer rated their health as "bad."

Table 2 presents the changes in the number of participants classified as cases and non-cases of anxiety (STAI-E) and depressive symptoms (BDI) from T0 to T1.

The Goodman confidence interval for contrasts between trinomial proportions showed that the number of cases and non-cases of anxiety and depressive symptoms determined by these instruments that maintained the same condition from $\mathrm{T} 0$ to $\mathrm{T} 1$ (b) was significantly higher than the number of changes observed (a), i.e., from non-cases to cases and from cases to non-cases $(p<0.05)$. However, an important increase in cases of anxiety (20.7\%) and in depressive symptoms $(13.7 \%)$ was observed at $\mathrm{T} 1$, even though the percentage of cases of anxiety and depressive symptoms diagnosed at T0 that remained at T1 (STAI, $68.97 \%$; BDI, $75.86 \%$ ) was greater than the percentage of changes.

Content analysis of the interviews conducted at T0 and T1 identified the categories described in the following, with the respective response percentages from the 49 patients.

T0:

Feelings in the pre-biopsy period

Positive (28.6\%): perception of well-being and the absence of problems;

Negative (71.4): perception of bodily changes, pain, nervousness, concerns relating to the possible severity of the disease, together with reports of discomfort by the participants in relation to the need for the tests and/or discomfort related to the interference of their symptoms in daily activities (food, sleep)

Understanding information about the diagnostic test 
Table 1 Sociodemographic, clinical, and psychosocial characteristics of the patients, according to a positive and negative cancer diagnosis

\begin{tabular}{|c|c|c|c|c|c|c|}
\hline & & \multicolumn{2}{|c|}{ Negative } & \multicolumn{2}{|c|}{ Positive } & \multirow[t]{2}{*}{$P$} \\
\hline & & $N=29$ & $\%$ & $N=20$ & $\%$ & \\
\hline Age* & $\begin{array}{l}20-59 \\
60 \text { or over }\end{array}$ & $\begin{array}{l}17 \\
12\end{array}$ & $\begin{array}{l}65.4 \\
52.2\end{array}$ & $\begin{array}{l}9 \\
11\end{array}$ & $\begin{array}{l}34.6 \\
47.8\end{array}$ & 0.35 \\
\hline \multirow[t]{2}{*}{ Years of education** } & $\begin{array}{l}0-3 \text { (low) } \\
4-7 \text { (medium) }\end{array}$ & $\begin{array}{l}10 \\
14\end{array}$ & $\begin{array}{l}71.4 \\
56.0\end{array}$ & $\begin{array}{l}4 \\
11\end{array}$ & $\begin{array}{l}28.6 \\
44.0\end{array}$ & 0.51 \\
\hline & $8 \geq$ (high) & 5 & 50.0 & 5 & 50.0 & \\
\hline Income** (minimum wage) & $\begin{array}{l}\leq 1 \\
>1\end{array}$ & $\begin{array}{l}15 \\
14\end{array}$ & $\begin{array}{l}57.7 \\
60.9\end{array}$ & $\begin{array}{l}11 \\
9\end{array}$ & $\begin{array}{l}42.3 \\
39.1\end{array}$ & 0.82 \\
\hline Living with a companion* & $\begin{array}{l}\text { Yes } \\
\text { No }\end{array}$ & $\begin{array}{l}17 \\
12\end{array}$ & $\begin{array}{l}56.7 \\
63.2\end{array}$ & $\begin{array}{l}13 \\
7\end{array}$ & $\begin{array}{l}43.3 \\
36.8\end{array}$ & 0.65 \\
\hline Social support* & $\begin{array}{l}\text { Yes } \\
\text { No }\end{array}$ & $\begin{array}{l}24 \\
5\end{array}$ & $\begin{array}{l}58.5 \\
62.5\end{array}$ & $\begin{array}{l}17 \\
3\end{array}$ & $\begin{array}{l}41.5 \\
37.5\end{array}$ & 0.83 \\
\hline Alcohol consumption AUDIT* & $\begin{array}{l}\text { Problem drinking } \\
\text { No problem }\end{array}$ & $\begin{array}{l}10 \\
19\end{array}$ & $\begin{array}{l}62.5 \\
57.6\end{array}$ & $\begin{array}{l}6 \\
14\end{array}$ & $\begin{array}{l}37.5 \\
42.4\end{array}$ & 1.00 \\
\hline Smoke* & $\begin{array}{l}\text { Yes } \\
\text { No }\end{array}$ & $\begin{array}{l}15 \\
14\end{array}$ & $\begin{array}{l}68.2 \\
51.8\end{array}$ & $\begin{array}{l}7 \\
13\end{array}$ & $\begin{array}{l}31.8 \\
48.2\end{array}$ & 0.24 \\
\hline Health self-assessment** & $\begin{array}{l}\text { Bad } \\
\text { Good }\end{array}$ & $\begin{array}{l}10 \\
19\end{array}$ & $\begin{array}{l}66.7 \\
55.8\end{array}$ & $\begin{array}{l}5 \\
15\end{array}$ & $\begin{array}{l}33.3 \\
44.2\end{array}$ & 0.47 \\
\hline \multirow[t]{2}{*}{ Time of lesion observation** } & $\begin{array}{l}<30 \text { days } \\
30 \text { to } 120 \text { days }\end{array}$ & $\begin{array}{l}10 \\
10\end{array}$ & $\begin{array}{l}66.7 \\
58.8\end{array}$ & $\begin{array}{l}5 \\
7\end{array}$ & $\begin{array}{l}33.3 \\
41.2\end{array}$ & 0.73 \\
\hline & $>120$ days & 9 & 52.9 & 8 & 47.1 & \\
\hline Anxiety symptoms* & $\begin{array}{l}\text { Case } \\
\text { Non-case }\end{array}$ & $\begin{array}{l}12 \\
17\end{array}$ & $\begin{array}{l}60.0 \\
58.6\end{array}$ & $\begin{array}{l}8 \\
12\end{array}$ & $\begin{array}{l}40.0 \\
41.4\end{array}$ & 1.00 \\
\hline Depressive symptoms* & $\begin{array}{l}\text { Case } \\
\text { Non-case }\end{array}$ & $\begin{array}{l}15 \\
14\end{array}$ & $\begin{array}{l}83.3 \\
45.2\end{array}$ & $\begin{array}{l}3 \\
17\end{array}$ & $\begin{array}{l}16.7 \\
54.8\end{array}$ & 0.02 \\
\hline
\end{tabular}

Considering $p$ value $<0.05$, all of the italic numbers presented a significant difference

$p<0.05$; *Fisher's exact test, **chi-square test, *** minimum wage in Brazil R $\$ 810,00$

Understood (63.3\%): patient's knowledge about the need for surgery to remove tissue (biopsy), and analyze and determine the diagnosis of a given "lesion"

Did not understand (36.7\%): absence of reports of the need for biopsy and the reasons this examination was required

Expectations regarding the diagnosis

Negative (61.2\%): patient's perception that their lesion could be serious, that it could be cancer, together with reports that indicated worry and fear concerning the diagnosis

Positive $(38.8 \%)$ : diminished awareness of the problem, statements about not knowing what was happening or even reports that described signs and symptoms and identified changes but in which the participant made no assumptions about the possible diagnosis or the severity of the lesion

T1:

Understanding the information about the diagnosis

Understood (69.0\%): understanding the diagnosis as cancer, whether or not they included minimizations or synonyms. This category also included reports indicating recognition of a problem that required treatment, whether or not they sought to understand its cause

Did not understand (31.0\%): lack of understanding of the information provided such that the participant's response made no mention of the diagnosis that had been discussed and the referral received
Table 2 Frequency of anxiety and depressive cases that changed between the time points $(n=29)$

\begin{tabular}{|c|c|c|c|}
\hline \multirow{2}{*}{$N=29$} & T0 & T0 & T0 \\
\hline & Non-case $\rightarrow$ case & Case $=$ case & Case $\rightarrow$ non-case \\
\hline Anxiety symptoms & $6(20.7 \%) a$ & $20(69.0 \%) b$ & $3(10.3 \%)$ a \\
\hline Depressive symptoms & $4(13.7 \%) \mathrm{a}$ & $22(75.9 \%) b$ & $3(10.4 \%)$ a \\
\hline
\end{tabular}

$p<0.05$; Goodman confidence interval for contrasts between trinomial proportions; a represents the percentage of cases that changed between the time points; $b$ represents the percentage of cases that did not change between the time points 
Feelings when faced with the diagnosis

Positive (17.2\%): positive feelings in the patient, feeling of well-being

Negative (58.6\%): concern, nervousness, sadness, anger, and anxiety following the news

Nonspecific reporting (NR) (24.1\%): neutrality, nonspecific responses, which do not allow us to identify positive or negative feelings

Dealing with the problem

Specifically related to treatment (27.6\%): desire to continue getting good treatment from the health professionals and accompanying the problem in search of a cure

Getting treated and "getting on with a normal life" (72.4 \%): included reports concerning the need for treatment and continue with their routine activities

Expectations regarding the dentist's approach

Regarding treatment (Treatment) $(72.4 \%)$ : desire to continue getting good treatment from the health professionals and accompanying the problem in search of a cure

Regarding communication (Communication) (17.2\%): desire to receive clear, truthful guidance and information about the problem;

Did not know/did not answer (NR) (10.3\%): patients who could not answer the question or did not wish to respond.

Expectations regarding the doctor's approach

Related to treatment of the disease (Treatment) $(65.5 \%)$ : expectation of being attended by a physician with sufficient skills to provide effective treatment, which would promote the cure of the problem

Related to the physician's behavior's (Behavior) (20.7\%): described the need for support, to maintain a dialogue with the doctor and that they would be trustworthy

Did not know/did not answer (NR) (13.8 \%): reports showing doubt in relation to the patient's expectations or the doctor, together with individuals who did not answer the question.

Satisfaction with the care received

Yes $(89.7 \%)$ : satisfaction with the care received by the dentist and the information provided, regardless of whether they had doubts about the diagnosis

No (10.3\%): dissatisfaction with the care and the desire for changes in how the dentist talked to them and treated them

Table 3 shows the association between the patient's sociodemographic characteristics $(n=49)$ with the interview categories. The category indicative of "negative feelings" in the pre-biopsy period (T0) was significantly more frequent among those who reported having an income above the minimum wage per capita $(87.0 \%$; $p=$ $0.04)$. In addition, the category negative expectations regarding the diagnosis was significantly higher among the elderly $(78.3 \% ; p=0.03)$ and among those with depressive symptoms $(78.3 \% ; p=0.01)$.

At T1, the category indicative of negative feelings following communication of the diagnosis was significantly more common among those who were classified as a case of anxiety ( $86.7 \% ; p=0.01)$. Two points should be noted: all those that presented depressive symptoms also reported negative feelings $(p=0.03)$ and there was a high frequency of nonspecific responses to this question (Table 4 ).

Table 5 shows the association between patient expectations of the dentists' and doctors' approach and the sociodemographic and psychosocial characteristics. The most frequent category in the theme of expectations regarding dentists indicated the desire that the dentist performs the treatment (Treatment) that most adequately resolved the problem. This category showed a significantly higher frequency among those who reported having social support ( $75 \% ; p=0.01)$. Those with no social support made no statement concerning how the dentist performed the service. Similarly, the most frequent responses concerning expectations of the doctor referred to the desire that they elect an efficient treatment (Treatment), with a significantly higher frequency of this category among those who reported having social support $(75 \% ; p=0.01)$. The same occurred among those with anxiety symptoms $(86.7 \% ; p=0.04)$.

\section{Discussion}

This study described sociodemographic, clinical, and lifestyle characteristics and the sense of social support among individuals during the process of oral cancer diagnosis, who were being treated at two reference centers in the interior of São Paulo, Brazil. Patient's reports regarding their perceptions of their health condition, the care they received, and their feelings and expectations concerning the problem and treatment were also obtained before the biopsy (T0) and after the diagnosis communication (T1). Associations between the characteristics and the categories obtained during the interviews allowed to identify important aspects of the health care practices for this population.

This study identified characteristics of patients suspected of having a malignant lesion in the oral region, showing similarities with other studies regarding patient mean age ranging from 50 to 60 years old [33]. Furthermore, risk habits that can facilitate the development of this disease, such as smoking $(68.2 \%)$ and alcohol abuse (62.5\%), were common among patients who received a cancer diagnosis. These percentages were higher compared with the general population $[2,3]$. The time between patient perception of the problem, by who received the cancer diagnosis, and the biopsy was an average of 4 months, which can negatively affect disease prognosis through worsening the extent of the disease $[4,40]$. This suggests the need for oral cancer preventative work sharing information across a population of patients at risk through general health information and specific information about symptoms. Prevention campaigns and continuous communication 
Table 3 Feelings and expectations (T0) related to diagnosis, according to the sociodemographic and psychosocial characteristics of the patients

\begin{tabular}{|c|c|c|c|c|c|c|c|c|c|c|c|}
\hline & & \multicolumn{5}{|c|}{ Feelings before biopsy } & \multicolumn{5}{|c|}{ Diagnosis expectations } \\
\hline & & \multicolumn{2}{|c|}{ Positive } & \multicolumn{2}{|c|}{ Negative } & \multirow[b]{2}{*}{$P$} & \multicolumn{2}{|c|}{ Positive } & \multicolumn{2}{|c|}{ Negative } & \multirow[b]{2}{*}{$P$} \\
\hline & & $N$ & $\%$ & $N$ & $\%$ & & $N$ & $\%$ & $N$ & $\%$ & \\
\hline \multirow[t]{2}{*}{ Sex* } & Male & 13 & 36.1 & 23 & 63.9 & \multirow[t]{2}{*}{0.07} & 14 & 38.9 & 22 & 61.1 & \multirow[t]{2}{*}{1.00} \\
\hline & Female & 1 & 7.7 & 12 & 92.3 & & 5 & 38.5 & 8 & 61.5 & \\
\hline \multirow[t]{2}{*}{ Age* } & $20-59$ & 10 & 38.5 & 16 & 61.5 & \multirow[t]{2}{*}{0.12} & 14 & 53.9 & 12 & 46.2 & \multirow[t]{2}{*}{0.03} \\
\hline & $>60$ & 4 & 17.4 & 19 & 82.6 & & 5 & 21.7 & 18 & 78.3 & \\
\hline \multirow[t]{3}{*}{ Years of education** } & $0-3$ & 3 & 21.4 & 11 & 78.6 & \multirow[t]{3}{*}{0.16} & 4 & 28.6 & 10 & 71.4 & \multirow[t]{3}{*}{0.63} \\
\hline & $4-7$ & 10 & 40.0 & 15 & 60.0 & & 11 & 44.0 & 14 & 56.0 & \\
\hline & $\geq 8$ & 1 & 10.0 & 9 & 90.0 & & 4 & 40.0 & 6 & 60.0 & \\
\hline \multirow[t]{2}{*}{ Income (minimum wage)* } & $\leq 1$ & 11 & 42.3 & 15 & 57.7 & \multirow[t]{2}{*}{0.04} & 14 & 53.9 & 12 & 46.1 & \multirow[t]{2}{*}{0.26} \\
\hline & $>1$ & 3 & 13.0 & 20 & 87.0 & & 16 & 69.6 & 7 & 30.4 & \\
\hline \multirow[t]{2}{*}{ Social support* } & Yes & 11 & 26.8 & 30 & 73.2 & \multirow[t]{2}{*}{0.67} & 15 & 36.6 & 26 & 63.4 & \multirow[t]{2}{*}{0.69} \\
\hline & No & 3 & 37.5 & 5 & 62.5 & & 4 & 50.0 & 4 & 50.0 & \\
\hline \multirow[t]{2}{*}{ Anxiety symptoms* } & Case & 7 & 35.0 & 13 & 65.0 & \multirow[t]{2}{*}{0.52} & 7 & 35.0 & 13 & 65.0 & \multirow[t]{2}{*}{0.76} \\
\hline & Non-case & 7 & 24.1 & 22 & 75.9 & & 12 & 41.4 & 17 & 58.6 & \\
\hline \multirow[t]{2}{*}{ Depression symptoms* } & Case & 4 & 22.2 & 14 & 77.8 & \multirow[t]{2}{*}{0.52} & 3 & 16.7 & 15 & 83.3 & \multirow[t]{2}{*}{0.01} \\
\hline & Non-case & 10 & 32.3 & 21 & 67.7 & & 16 & 51.6 & 15 & 48.4 & \\
\hline
\end{tabular}

Considering $p$ value $<0.05$, all of the italic numbers presented a significant difference

$p<0.05$; *Fisher's exact test, **chi-square test, ***minimum wage in Brazil R $\$ 810,00$

training during undergraduate programs could allow early detection and better prognosis of oral diseases, providing patients with a better quality of life [4].
In T0, a high prevalence of anxiety and depressive symptoms was observed, which is commonly identified among cancer patients $[34,41]$. In this phase, $60 \%$ of cancer patients
Table 4 Feelings after cancer disclosure (T1), according to the sociodemographic and psychosocial characteristics of the patients

\begin{tabular}{|c|c|c|c|c|c|c|c|c|}
\hline & & \multicolumn{2}{|c|}{ Positive } & \multicolumn{2}{|c|}{ Negative } & \multicolumn{2}{|c|}{ Unspecific reports } & \multirow[b]{2}{*}{$P$} \\
\hline & & $N$ & $\%$ & $N$ & $\%$ & $N$ & $\%$ & \\
\hline \multirow[t]{2}{*}{ Sex } & Male & 3 & 12.5 & 14 & 58.3 & 7 & 29.2 & 0.19 \\
\hline & Female & 2 & 40.0 & 6 & 60.0 & - & - & \\
\hline \multirow[t]{2}{*}{ Age } & $20-59$ & 2 & 11.8 & 10 & 58.8 & 5 & 29.4 & 0.52 \\
\hline & $>60$ & 3 & 25.0 & 7 & 58.3 & 2 & 16.7 & \\
\hline \multirow[t]{3}{*}{ Years of education } & $0-3$ & 3 & 30.0 & 6 & 60.0 & 1 & 10 & 0.48 \\
\hline & $4-7$ & 1 & 7.1 & 8 & 57.1 & 5 & 35.7 & \\
\hline & $\geq 8$ & 1 & 20.0 & 3 & 60.0 & 1 & 20.0 & \\
\hline \multirow[t]{2}{*}{ Income (minimum wage)* } & $\leq 1$ & 2 & 13.3 & 11 & 73.3 & 2 & 13.4 & 0.35 \\
\hline & $>1$ & 3 & 21.4 & 6 & 42.9 & 5 & 36 & \\
\hline \multirow[t]{2}{*}{ Social support } & Yes & 3 & 12.5 & 15 & 62.5 & 6 & 25.0 & 0.33 \\
\hline & No & 2 & 40.0 & 2 & 40.0 & 1 & 20.0 & \\
\hline \multirow[t]{2}{*}{ Anxiety symptoms } & Case & 1 & 6.7 & 13 & 86.7 & 1 & 6.7 & 0.01 \\
\hline & Non-case & 4 & 28.6 & 4 & 28.6 & 6 & 42.9 & \\
\hline \multirow[t]{2}{*}{ Depressive symptoms } & Case & - & - & 7 & 100.0 & - & - & 0.03 \\
\hline & Non-case & 5 & 22.7 & 10 & 45.5 & 7 & 31.8 & \\
\hline
\end{tabular}

Considering $p$ value $<0.05$, all of the italic numbers presented a significant difference $p<0.05$; chi-square test, *minimum wage in Brazil $\mathrm{R} \$ 810,00$ 
Table 5 Patients' expectations of the physician's treatment (T2), according to their sociodemographic and psychosocial characteristics

\begin{tabular}{|c|c|c|c|c|c|c|c|c|c|c|c|c|c|c|}
\hline & \multicolumn{7}{|c|}{ With dentist } & \multicolumn{7}{|c|}{ With doctor } \\
\hline & \multicolumn{2}{|c|}{ Treatment } & \multicolumn{2}{|c|}{ Communication } & \multicolumn{2}{|c|}{ Don't know } & \multirow[b]{2}{*}{$P$} & \multicolumn{2}{|c|}{ Treatment } & \multicolumn{2}{|c|}{ Behavior } & \multicolumn{2}{|c|}{ Don't know } & \multirow[b]{2}{*}{$P$} \\
\hline & $N$ & $\%$ & $N$ & $\%$ & $N$ & $\%$ & & $N$ & $\%$ & $N$ & $\%$ & $N$ & $\%$ & \\
\hline \multicolumn{15}{|l|}{ Sex } \\
\hline Male & 17 & 70.8 & 4 & 16.7 & 3 & 12.5 & 0.67 & 15 & 62.5 & 6 & 25.0 & 3 & 12.5 & 0.44 \\
\hline Female & 4 & 80.0 & 1 & 20.0 & - & - & & 4 & 80.0 & - & - & 1 & 20.0 & \\
\hline \multicolumn{15}{|l|}{ Age } \\
\hline $20-59$ & 13 & 76.5 & 2 & 11.8 & 2 & 11.8 & 0.64 & 9 & 52.9 & 6 & 35.3 & 2 & 11.8 & 0.07 \\
\hline$>60$ & 5 & 66.7 & 3 & 25.0 & 1 & 8.3 & & 10 & 83.3 & - & - & 2 & 16.7 & \\
\hline \multicolumn{15}{|c|}{ Years of education } \\
\hline $0-3$ & 7 & 70.0 & 1 & 10.0 & 2 & 20.0 & 0.46 & 7 & 70.0 & - & - & 3 & 30.0 & 0.16 \\
\hline $4-7$ & 11 & 78.6 & 2 & 14.3 & 1 & 7.1 & & 9 & 64.3 & 4 & 28.6 & 1 & 7.1 & \\
\hline$\geq 8$ & 3 & 60.0 & 2 & 40.0 & - & - & & 3 & 60.0 & 6 & 40.0 & - & - & \\
\hline \multicolumn{15}{|c|}{ Income (minimum wage)* } \\
\hline$\leq 1$ & 13 & 86.7 & 2 & 13.3 & - & - & 0.24 & 9 & 60.0 & 5 & 33.3 & 1 & 6.7 & 0.37 \\
\hline$>1$ & 8 & 57.2 & 3 & 21.4 & 3 & 21.4 & & 10 & 71.4 & 1 & 7.2 & 3 & 21.4 & \\
\hline \multicolumn{15}{|c|}{ Social support } \\
\hline Yes & 18 & 75.0 & 5 & 20.8 & 1 & 4.2 & 0.01 & 18 & 75.0 & 5 & 20.8 & 1 & 4.2 & 0.01 \\
\hline No & 3 & 60.0 & - & - & 2 & 40.0 & & 1 & 20.0 & 1 & 20.0 & 3 & 60.0 & \\
\hline \multicolumn{15}{|c|}{ Anxiety symptoms } \\
\hline Case & 9 & 60.0 & 5 & 33.3 & 1 & 6.7 & 0.06 & 13 & 86.7 & 2 & 13.3 & - & - & 0.04 \\
\hline Non-case & 12 & 85.7 & - & - & 2 & 14.3 & & 6 & 42.9 & 4 & 28.6 & 4 & 28.6 & \\
\hline \multicolumn{15}{|c|}{ Depression symptoms } \\
\hline Case & 5 & 71.4 & 2 & 28.6 & - & - & 0.44 & 5 & 71.4 & 2 & 28.6 & - & - & 0.45 \\
\hline Non-case & 16 & 72.7 & 3 & 13.6 & 3 & 13.6 & & 14 & 63.6 & 4 & 18.2 & 4 & 18.2 & \\
\hline
\end{tabular}

Considering $p$ value $<0.05$, all of the italic numbers presented a significant difference

$p<0.05$; chi-square test, *minimum wage in Brazil R $\$ 810,00$

had anxiety symptoms and the same group of patients had significantly higher prevalence of depressive symptoms compared with those who received a diagnosis of benign lesion. These data suggest the importance of systematic investigation of the psychosocial aspects of individuals with this condition $[15,21,34,41]$. This can be possible by providing supplementary education to clinicians during communication training programs with psychosocial focus. The training can include formal protocols about bad news communication, techniques of psychological interview, and the management of standard instruments. The ability of identifying problems such distress and lack of social support can decrease the barriers between clinicians and patients and prevent untreated psychological, psychosocial, or psychiatric symptoms $[9,19,26,31$, 42]. Following patients from the beginning of the diagnostic process is essential for identifying those aspects that can thus interfere in patient's perceptions of their health- and careseeking behavior $[6,9,10,15,34]$.

The analysis of the subcategory negative feelings, identified in both phases, suggests that listening to these patients from the onset of the diagnostic process can minimize the impact to all involved [15]. Reports that fit into the negative feelings category, which was related to the patients' concerns with the severity of the disease, were significantly more frequent among patients with higher income. This is probably due to the fact that individuals in better socioeconomic conditions may have higher educational level and be able to discuss their health status with clinicians [14]. Clinicians are expected to provide reliable information about the cancer diagnosis and treatment. Thus, clinicians should know how to deal with negative feelings of their patients and provide adequate psychosocial support. Thus, reports of concern occurred especially among elderly patients who had already admitted the possibility of having a serious disease. Similar concerns were observed among patients with depressive symptoms. Advanced age may be associated with greater health impairment, awareness of the condition, and its potential severity [41].

Even though most patients reportedly understood the information provided by the dentist in relation to the biopsy and the resulting diagnosis, in accordance with the general guidelines of the service, some patients did not mention the word cancer. Moreover, some patients were not able to reproduce the 
information provided by the health professionals. This may be due to feelings of shock during the diagnosis communication or a form of emotional control [26]. However, leaving the consultation with the information provided by physician is important, since this increases the likelihood that patients will seek the recommended treatment, a factor that is even more relevant when it comes to a diagnosis of cancer [29, 40]. Some consideration should be given to cultural differences that can affect the physician's decision to fully or partially communicate the diagnosis $[19,20]$.

The ability of communicating bad news is a skill required among doctors and dentists; however, it can be an aversive condition for all those involved [16, 19, 26, 43, 44]. Some steps can help clinicians feel more confident during diagnostic disclosure [8]. Preparing the information and the setting of interaction and having sufficient time for the conversation are important aspects to be considered before such disclosure. It is also important to investigate what the patients already know about their health and what they want to know. The information should be given as gradually and clearly as possible considering the characteristics of the patients and aspects mentioned above. The clinicians have to be prepared to respond to the patient's reactions and to close the conversation identifying what they had understood about the information provided [23].

In this study, it seems that patient satisfaction with the care received is related to understanding the information provided $[9,10]$. Offering clear and truthful information is a prerequisite for establishing a bond of trust and hence the patients' satisfaction with the care received [45]. Thus, the participants presented reports indicative of satisfaction with the dentists independent of their characteristics, in contrast to that reported by other authors $[9,11]$. The reports of patients' expectations (T1) in relation to the behavior of the physicians are also worth highlighting, particularly how patients expected the dentist to continue communicating with them, offering support, opportunities for dialogue, and truthful and clear information [10, 12].

Besides the aspects mentioned above, those who left the consultation feeling they were fully informed of their problem tended to report greater emotional control, perceiving the information as a coping resource [9]. Although this study did not measure ways of coping using an objective instrument, in $\mathrm{T} 1$, the reports identified that some patients would immediately look for cancer treatment and try to lead a normal life. It can be inferred that patients sought to maintain control of the situation by continuing to perform daily activities and trying not to let the possible emotional consequences interfere with the treatment [9].

The findings identified in this study could facilitate the planning of care by physicians and indicate the importance of the clarity and truthfulness of the information provided, particularly during disclosure of the cancer diagnosis.
Listening and accepting the patient's demands from the first consultation onward can assist the doctor or dentist in tracing important psychosocial aspects that are known to interfere negatively in some patients' perceptions of their health condition and, consequently, in their adhesion to treatment. Moreover, the findings indicate the need for educational and health public policies concerning delivery of information about the psychological aspects of patients with cancer diagnosis and about the consequences of information inadequately provided for patients. Regarding the limitations of this study, it is clear that the small number of participants may have affected the results of the statistical analyses. Thus, multicenter and longitudinal studies should be performed focusing on the psychological impact caused by the process of cancer diagnosis, while aiming to minimize their suffering and promote treatment adherence and, consequently, improve the prognosis of the disease.

\section{Compliance with ethical standards}

Conflict of interest The authors declare that they have no competing interests.

\section{References}

1. Majchrzak E, Szybiak B, Wegner A, Pienkowski P, Pazdrowski J, Luczewski L, Marcin S, Pawel G, Julian M, Wojciech G (2014) Oral cavity and oropharyngeal squamous cell carcinoma in young adults: a review of the literature. Radiol Oncol 48(1):1-10. doi:10. 2478/raon-2013-0057

2. Berg CJ, Thomas AN, Merterns AC, Schauer GL, Pinsker EA, Ahluwalia JA (2013) Correlates of continued smoking versus cessation among survivors of smoking-related cancers. Psychooncology 22:799-806. doi:10.1002/pon.3077

3. O’Brien K, Roe B, Low C, Deyn L, Rogers LS (2012) An exploration of the perceived changes in intimacy of patients' relationships following head and neck cancer. J Clin Nurs 21:2499-2508. doi:10.1111/j.1365-2702.2012.04162.x

4. Johnson NW, Warnakulasuriya S, Gupta PC, Dimba E, Chindia M, Otoh EC, Sankaranarayanan R, Califano J, Kowalski L (2011) Global oral health inequalities in incidence and outcomes for oral cancer: causes and solutions. Adv Dent Res 23:237-246. doi:10. 1177/0022034511402082

5. Djan R, Penington A (2013) A systematic review of questionnaires to measure the impact of appearance on quality of life for head and neck cancer patients. J Plast Reconstr Aesthet Surg 1-13. doi:10. 1016/j.bjps.2013.01.007

6. Yucel B, Akkaş EA, Okur Y, Eren A, Eren MF, Karapınar H, Babacan NA, Kılıçk S (2014) The impact of radiotherapy on quality of life for cancer patients: a longitudinal study. Support Care Cancer 22:2479-2487. doi:10.1007/s00520-014-2235-y

7. Spiegel W, Zidek T, Maier M, Vutuc C, Isak K, Karlic H, Micksche M (2009) Breaking bad news to cancer patients: survey and analysis. Psychooncology 18:179-186. doi:10.1002/pon.1383

8. Fujimori M, Uchitomi Y (2009) Preferences of cancer patients regarding communication of bad news: a systematic literature review. 
Japanese Journal Clinical Oncology 39:201-216. doi:10.1093/jjco/ hyn 159

9. Fagerlind H, Kettis A, Glimelius B, Ring L (2013) Barriers against psychosocial communication: oncologists' perceptions. J Clin Oncol 31:3815-3822. doi:10.1200/JCO.2012.45.1609

10. Repetto L, Piselli P, Raffaele M, Locatelli C (2009) Communicating cancer diagnosis and prognosis: when the target is the elderly patient—a GIOGer study. Eur J Cancer 45:374-383. doi:10.1016/j. ejca.2008.08.020

11. Sastre MTM, Sorum PC, Mullet E (2011) Breaking bad news: the patient's viewpoint. Health Commun 26:649-655. doi:10.1080/ 10410236.2011.561919

12. Durusoy R, Karaca B, Junushova B, Uslu R (2011) Cancer patients' satisfaction with doctors and preferences about death in a university hospital in Turkey. Patient Educ Couns 85:e285-e290. doi:10. 1016/j.pec.2011.03.010

13. Kwok C, White K (2014) Perceived information needs and social support of Chinese-Australian breast cancer survivors. Support Care Cancer 22:2651-2659. doi:10.1007/s00520-014-2252-x

14. Wang D, Guo CB, Peng X, Su YJ, Chen F (2011) Is therapeutic non-disclosure still possible? A study on the awareness of cancer diagnosis in China. Support Care Cancer 19:1191-1195. doi:10. 1007/s00520-010-0937-3

15. Dégi CL (2009) Non-disclosure of cancer diagnosis: an examination of personal, medical, and psychosocial factors. Support Care Cancer 17:1101-1107. doi:10.1007/s00520-008-0568-0

16. Stajduhar KI, Thorne SE, McGuinness L, Kim-Sing C (2010) Patient perceptions of helpful communication in the context of advanced cancer. J Clin Nurs 19:2039-2047. doi:10.1111/j.13652702.2009.03158.x

17. Berkman CS, Ko E (2010) What and when Korean American older adults want to know about serious illness. J Psychosoc Oncol 28: 244-259. doi:10.1080/07347331003689029

18. Beqiri A, Toci E, Sallaku A, Qirjako G, Burazeri G (2012) Breaking bad news in a southeast European population: a survey among cancer patients in Albania. J Palliat Med 15:10100-11105. doi:10. 1089/jpm.2012.0068

19. Valisadeh L, Zamanzadeh V, Rahmani A, Howard F, Nikanfar A, Ferguson C (2012) Cancer disclosure: experiences of Iranian cancer patients. Nursing and Health Science 14:250-256. doi:10.1111/j. 1442-2018.2012.00686.x

20. Zamanzadeh V, Rahmani A, Valizadeh L, Ferguson C, Hassankhani H, Nikanfar A, Howard F (2013) The taboo of cancer: the experiences of cancer disclosure by Iranian patients, their family members and physicians. Psychooncology 22:396-402. doi:10.1002/pon. 2103

21. Liénard A, Merckaert I, Libert Y, Delvaux N, Marchal S, Boniver J (2010) Is it possible to improve residents breaking bad news skills? A randomised study assessing the efficacy of a communication skills training program. Br J Cancer 103:171-177. doi:10.1038/sj. bjc.6605749

22. Stiefel F, Thorne SE, McGuinness L, Kim-Sing C (2012) Medical students' skills and needs for training in breaking bad news. J Cancer Educ 28:187-191. doi:10.1007/s13187-012-0420-6

23. Newton JT, Fiske J (1999) Breaking bad news: a guide for dental healthcare professionals. Br Dent J 186:278-281. doi:10.1038/sj. bdj. 4800087

24. Newton JT (2010) Reactions to cancer: communicating with patients, family and carers. Oral Oncol 46:442-444. doi:10.1016/j. oraloncology.2010.03.015

25. Curtin LB, Finn LA, Czosnowski QA, Whitman CB, Cawley MJ (2011) Computer-based simulation training to improve learning outcomes in mannequin-based simulation exercises. Am J Pharm Educ 75:1-6. doi:10.5688/ajpe756113

26. Lobb EA, Halkett GKB, Nowak AK (2011) Patient and caregiver perceptions of communication of prognosis in high grade glioma.
Journal of Neurooncology 104:315-322. doi:10.1007/s11060-0100495-Z

27. Paula JM, Sonobe HM, Nicolussi AC, Zago MMF, Sawada NO (2012) Symptoms of depression in patients with cancer of the head and neck undergoing radiotherapy treatment: a prospective study. Rev Lat Am Enfermagem 20:362-368. doi:10.1590/S010411692012000200020

28. Rhoten BA, Deng J, Dietrich MS, Murphy B, Ridner SH (2014) Body image and depressive symptoms in patients with head and neck cancer: an important relationship. Support Care Cancer 22: 3053-3060. doi:10.1007/s00520-014-2312-2

29. Figg WD, Smith EK, Price DK, English BC, Thurman PW, Steinberg SM, Emanuel E (2012) Disclosing a diagnosis of cancer: where and how does it occur? J Clin Oncol 28:3630-3635. doi:10. 1200/JCO.2009.24.6389

30. Fujimori M, Shirai Y, Asai M, Kubota K, Katsumata N, Uchitomi Y (2014) Effect of communication skills training program for oncologists based on patient preferences for communication when receiving bad news: a randomized controlled. Trial J Clin Oncol 32. DOI: 10.1200/JCO.2013.51.2756

31. Gonzalez P, Castañeda SF, Dale J, Medeiros EA, Buelna C, Nuñez A (2014) Spiritual well-being and depressive symptoms among cancer survivors. Support Care Cancer 22:2393-2400. doi:10. 1007/s00520-014-2207-2

32. Uitdehaag MJ, Van der Veklen L, Boer MF, Spaander MCW, Steyerberg EW, Kuipers EJ (2012) Recordings of consultations are beneficial in the transition from curative to palliative cancer care: a pilot-study in patients with esophageal or head and neck cancer. Eur J Oncol Nurs 16:109-114. doi:10.1016/j.ejon.2011. 04.006

33. Kilbourn KM, Derek A, Costenaro A, Lusczakoski K, Borrayo E, Raben D (2013) Feasibility of ease: a psychosocial program to improve symptom management in head and neck cancer patients. Support Care Cancer 21:191-200. doi:10.1007/s00520-012-1510-Z

34. Liao MN, Chen MF, Chen SC, Chen PL (2008) Uncertainty and anxiety during the diagnostic period for women with suspected breast cancer. Cancer Nurs 31:274-283. doi:10.1097/01.NCC. 0000305744.64452.fe

35. Spielberger CD, Gorsuch RL, Lushene RE (1970) State-Trait Anxiety Inventory manual. Consulting Psychologists Press, Palo Alto, USA

36. Beck AT, Ward CH, Mendelson M, Mock J, Erbaugh J (1961) An inventory for measuring depression. Arch Gen Psychiatry 4:561571. doi:10.1001/archpsyc. 1961.01710120031004

37. Barbor TF, Higgins-Biddle JC, Saunders JB, Monteiro MG (1992) AUDIT - the alcohol use disorders identification test: guidelines for use in primary health care. WHO (World Health Organization/ PSA), Geneva, Switzerland, pp 1-29

38. Bardin L (2009) Análise de Conteúdo. Edições 70, LDA, Lisboa, Portugal

39. Corp S (2013) Stata Statistical Software: release 13. StataCorp LP, College Station

40. Campos JLG, Chagas JFS, Magna L (2007) A. Fatores de atraso no diagnóstico do câncer de cabeça e pescoço e sua relação com sobrevida e qualidade de vida. [Delay factors in the diagnosis of head and neck cancer and its relationship to survival and life quality] Revista Brasileira de Cirurgia de Cabeça e Pescoço, 36, 65-68. http://sbccp.netpoint.com.br/ojs/index.php/revistabrasccp/article/ view/27/22

41. Suzuki N, Ninomiya M, Maruta S, Hosonuma S, Nishigaya $Y$, Kobayashi Y, Kiguchi K, Ishizuka B (2011) Psychological characteristics of Japanese gynecologic cancer patients after learning the diagnosis according to the hospital anxiety and depression scale. J Obstet Gynaecol Res 37:800-808. doi:10.1111/j.1447-0756.2010. 01437.x 
42. Fukui S, Ogawa K, Ohtsuka M, Fukui N (2008) A randomized study assessing the efficacy of communication skill training on patients' psychologic distress and coping. Cancer 113(6):14621470. doi:10.1002/encr.23710.

43. Liénard A, Merckaert I, Libert Y, Delvaux N, Marchal S, Boniver J, Etienne AM, Klastersky J, Reynaert C, Scalliet P, Slachmuylder JL, Razavi D (2006) Factors that influence cancer patients' anxiety following a medical consultation: impact of a communication skills training programme for physicians. Ann Oncol 17:1450-1458. doi: 10.1002/pon. 1262

44. Nwankwo KC, Ezeome E (2011) The perceptions of physicians in southeast Nigeria on truth-telling for cancer diagnosis and prognosis. J Palliat Med 14:700-703. doi:10.1089/jpm.2010.0440

45. Chittem M, Norman P, Harris PR (2013) Relationships between perceived diagnostic disclosure, patient characteristics, psychological distress and illness perceptions in Indian cancer patients. Psychooncology 22:1375-1380. doi:10.1002/pon.3149 